\title{
Effects of Microwave Power on Extraction Kinetic of Anthocyanin from Blueberry Powder considering Absorption of Microwave Energy
}

\author{
Hongkun Xue, Hao Xu, Xiaorui Wang, Liuyang Shen, Han Liu, Chai Liu, Qingyu Qin, \\ Xianzhe Zheng $\mathbb{D}$, and Qingyan Li
}

College of Engineering, Northeast Agricultural University, Harbin 150030, China

Correspondence should be addressed to Xianzhe Zheng; zhengxz2013@163.com

Received 5 November 2017; Accepted 14 January 2018; Published 28 February 2018

Academic Editor: Hong-Wei Xiao

Copyright (C) 2018 Hongkun Xue et al. This is an open access article distributed under the Creative Commons Attribution License, which permits unrestricted use, distribution, and reproduction in any medium, provided the original work is properly cited.

\begin{abstract}
Microwave power as directly controlled parameter determines the absorption of microwave energy inside extraction vial and the yield of objective component in microwave-assisted extraction (MAE). The aim of this study was to elucidate the effects of microwave powers on the yield of anthocyanin from blueberry (Vaccinium spp.) powder based on the absorption of microwave energy in extracts under MAE. Rising microwave powers have little effect on the distribution of microwave energy in extraction vial, but increase its temperature. The simulation results indicated that strength of electrical field tends to decay trend along with microwave irradiation; however, temperatures have the highest level in center location in an extraction vial. High microwave power strongly breaks cell wall of blueberry to open diffusion route of interior anthocyanin toward extraction solvent. A critical extraction temperature of $50.75 \pm 0.88^{\circ} \mathrm{C}$ is obtained with the highest anthocyanin yield under MAE. Three monomers of anthocyanin including pelargonidin, cyanidin, and delphinidin are, respectively, of the highest content of $1.02 \mu \mathrm{g} / \mathrm{mL}, 0.66 \mu \mathrm{g} / \mathrm{mL}$, and $0.31 \mu \mathrm{g} / \mathrm{mL}$. The research results contribute to the improvement of efficiency of microwave energy and yield of anthocyanin.
\end{abstract}

\section{Introduction}

Blueberry (Vaccinium spp.) fruit contains abundant anthocyanin [1], which has great medical and nutritional value in antioxidation, antiaging, and protecting cardiovascular and cerebrovascular diseases [2]. Microwave-assisted extraction (MAE) is a promising extraction method to extract compounds from plant-based materials, for example, flavonoids [3], pectin [4], phenolic compounds [5], and oil [6]. MAE is suitable for the extraction of anthocyanin from blueberry fruits [7]. Already, studies about microwave extraction of bioactive components mostly focus on the extraction properties, parameter optimization, and the yield of objective components. Zheng et al. [8] found that the solid-to-liquid ratio has the most important effect on the anthocyanin extraction kinetic from blueberry powder, followed by the ethanol concentration and extraction temperature, and the extraction time of anthocyanin from blueberry powder in MAE has the least effect. The coupling transfer of mass and heat at the same direction speeds up the extraction process at higher extraction yield [9]. The absorption of microwave energy of material tends to variable trend inside material along microwave incident direction [10], which determines the distribution and change of temperature in extraction vial. The nonuniform distribution of microwave energy results from the changes of dielectric properties and the decay of electric field strength in extraction solution. In MAE, microwave irradiation into extraction vial forms complex interaction of absorption of microwave energy. Existing studies considered the microwave power as the uniform distribution in extraction vial, however, producing localized hot and cold points to cause the nonuniform distribution of heating and degradation of components extracted. Microwave power dominates the absorption and conversion behaviors of microwave energy inside extraction vial, which obviously depended on its dielectric properties [11]. Some researches were done to reveal the relevance of microwave power and the absorption of microwave energy 
in extraction vial. Han et al. [12] and Chan et al. [13] defined microwave absorption coefficient to characterize effects of the dielectric properties on the absorption amount of microwave energy in extraction vial. Chan et al. [14] explained the absorption of the microwave energy in nature considering the changes of dielectric properties of the extraction vial in MAE process. Therefore, the investigation of microwave power contributes to improving the utilization of microwave energy and the yield of anthocyanin. The model of absorption of the microwave energy as the function of microwave power may be built based on the changes of dielectric properties as the function of temperature in the extraction vial.

In microwave heating, electromagnetic field causes the rapid rotation of polar molecules and rapid movement of ionic in polar material to form the violent frication [15]. Absorption of microwave energy in extraction vial generates the volumetric heating to determine the temperature distribution, which influences the extraction and degradation of components extracted in MAE [16]. Microwave volumetric heating instantaneously raises the temperature to accelerate the pressure build-up inside cell of plant-based materials. This pressure causes the rupture of the cell wall to release the component into the extraction solution to accelerate the diffusion of component out of the source material [17]. Computer simulation is an effective method to analyze the process of extraction and degradation of components extracted in MAE. Navarrete et al. [18] simulated the changes of yield and evaporation of essential oils from Lavandin super under different temperatures in MAE. Chan et al. [14] studied the diffusion of antioxidant compounds from cocoa leaves considering absorbed microwave energy in MAE. In addition, regression models from response surface methodology and artificial neural network are applied to optimize the process parameters in MAE [19].

The absorption of microwave energy inside extraction vial was evenly considered as the uniform distribution. However, both the microwave propagation at conversion between electric field and magnetic field and the dissipation of microwave energy at exponential attenuation in extraction vial result in nonuniform distribution of microwave energy, which give rise to the "hot" and "cold" point of temperature in vial. This nonuniform distribution of microwave energy causes the uncertainty of effect of microwave power on the extraction process of objective components. To explore the distribution of microwave energy and temperature inside extraction vial may conduce to explaining the microwave extraction process.

To the authors' best effort, however, little information was published about the effects of microwave powers on the absorption of microwave energy inside extraction vial and yield of anthocyanin from blueberry powder in MAE. Based on the above-mentioned studies, to elucidate microwave power on the extraction of anthocyanin from blueberry powder, the objectives of this study are as follows:

(1) To elucidate the distribution of temperature in extraction vial under different microwave powers

(2) To analyze the effects of microwave power on the yield and degradation rate of anthocyanin from blueberry powder.

\section{Mathematical Model Development}

In working microwave equipment, there exists complex interaction between the microwave irradiation and material processed. The electric field strength $E$ of prorogation of microwave in cavity obeys Maxwell's law as

$$
\nabla \times \frac{1}{\mu_{r}}(\nabla \times E)-k_{0}^{2}\left(\varepsilon_{r}-\frac{j \delta}{\omega \varepsilon_{0}}\right) E=0,
$$

where $k_{0}$ is wave number of free space, $E$ is electric field strength, $\mathrm{V} / \mathrm{m}, \mu_{r}$ is permeability of dielectric constant, $\varepsilon_{r}$ is relative dielectric constant, $\omega$ is angular velocity, $\mathrm{rad} / \mathrm{s}$, $\varepsilon_{0}$ is vacuum dielectric constant, $k_{0}$ is thermal conductivity, $\mathrm{W} / \mathrm{m} \cdot \mathrm{K}, j$ is imaginary unit, and $\delta$ is electric conductivity, $\mathrm{S} / \mathrm{m}$.

According to the law of energy conservation, the absorption of microwave energy in the extraction vial is consumed by the thermal accumulation and thermal diffusion as shown in

$$
\rho C_{p} \frac{\partial T}{\partial t}+\rho C_{p} u \cdot \nabla T=\nabla \cdot(k \nabla T)+Q
$$

where $\rho$ is material density, $\mathrm{kg} / \mathrm{m}^{3}, C_{p}$ is specific heat capacity, $\mathrm{J} / \mathrm{kg} \cdot \mathrm{K}, k$ is coefficient of thermal diffusion, $\mathrm{W} / \mathrm{m} \cdot \mathrm{K}, T$ is extraction temperature, ${ }^{\circ} \mathrm{C}, Q$ is heat source, $\mathrm{W} / \mathrm{m}^{3}, t$ is extraction time, $\mathrm{s}$, and $u$ is current velocity, $\mathrm{m} / \mathrm{s}$. Convection was ignored in the energy and species balance equations. Mass diffusion was not considered in the species balance equation.

In microwave field, the intensity frication of polar molecule in dielectric material generates the volumetric heating, which depends on the electric loss factor of material and electric field strength as shown in

$$
Q=2 \pi f \varepsilon_{0} \varepsilon^{\prime \prime} E^{2}
$$

where $\varepsilon^{\prime \prime}$ is dielectric loss factor, $f$ is microwave frequency of $2450 \mathrm{MHz}, \varepsilon_{0}$ is vacuum dielectric constant, and $E$ is electric field intensity, $\mathrm{V} / \mathrm{m}$.

For (2), initial conditions were set at $C=C_{0}(t=$ 0 ) and $T=T_{0}$, where $C_{0}$ is initial concentration and $T_{0}$ is room temperature, $20^{\circ} \mathrm{C}$. Initial temperature and anthocyanin content were uniform in the extraction vial. Boundary conditions were set as no mass transfer and heat convection at the interface between solvent and glass as (4) and (5), respectively.

$$
\begin{aligned}
\nabla C & =0 \\
n(k \nabla T) & =h\left(T-T_{\infty}\right),
\end{aligned}
$$

where $T_{\infty}$ is the ambient temperature, $25^{\circ} \mathrm{C}$, and $h$ is the coefficient of convective heat transfer, $40 \mathrm{~W} / \mathrm{m}^{2} \cdot \mathrm{K}$.

From (3), the absorption amount of microwave energy depends on the dielectric properties and electrical field 


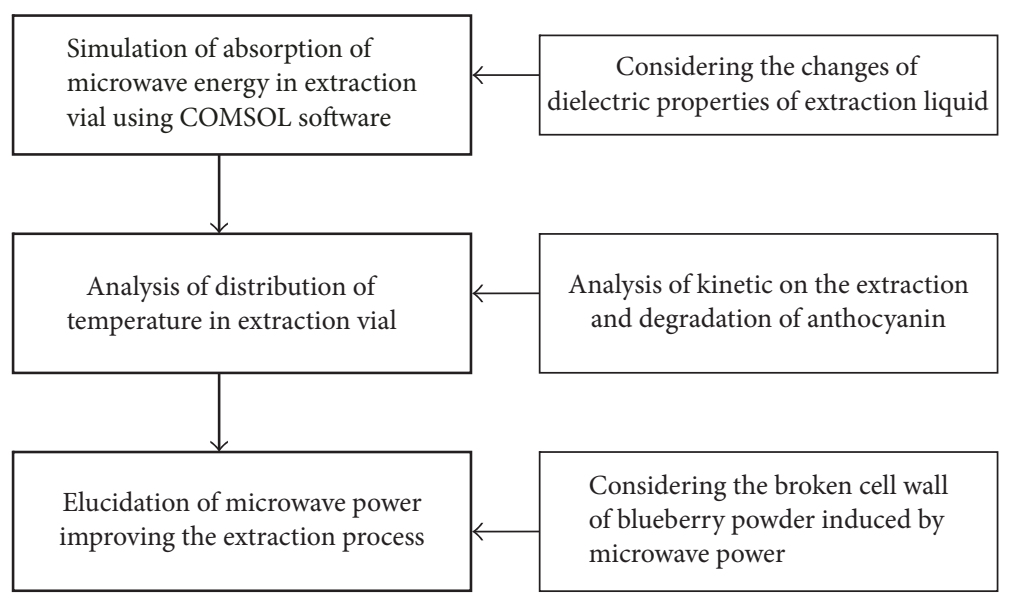

FIGURE 1: Research route for investigation of microwave powers on extraction and degradation of anthocyanin from blueberry powder considering absorption of microwave energy.

strength in extraction vial. The dielectric properties of extraction liquid as the function of temperature are shown as follows [20]:

$$
\begin{aligned}
& \varepsilon^{\prime}=32.0944+0.2263 T-0.0017 T^{2} \quad\left(R^{2}=0.9690\right) \\
& \varepsilon^{\prime \prime}=18.8079-0.0969 T-0.0008 T^{2}\left(R^{2}=0.9840\right) .
\end{aligned}
$$

To estimate the degradation kinetic of anthocyanin monomers, the changes of delphinidin, cyanidin, and pelargonidin follow Lorenz's function, in

$$
y=y_{0}+\frac{a}{1+\left(\left(x-x_{0}\right) / k\right)^{2}},
$$

where $y$ is content of anthocyanin monomer including delphinidin cyanidin and pelargonidin, $\mu \mathrm{g} / \mathrm{mL}, x_{0}$ is microwave power when $y$ reaches maximum value, $y_{0}$ is initial anthocyanin monomer content, $\mu \mathrm{g} / \mathrm{mL}, a$ is constant, and $k$ is constant of extraction yield.

\section{Materials and Methods}

3.1. Preparations of Blueberry Powder. Fresh wild blueberries were collected from the Xiangfang farm of Harbin in China. Blueberries were selected, cleaned, and then placed into a cool storage room of refrigerator at $4^{\circ} \mathrm{C}$. The cooling stored blueberries were taken out from refrigerator and smashed by using fruit pulping machine (Philips-30, Zhuhai, China) to acquire the blueberries purees. Then, the blueberries purees were frozen in a TD-50 freezing-vacuum dryer (Shanghai Pudong Freeze Drying Equipment Co., Ltd., Shanghai, China) at temperature of $-18^{\circ} \mathrm{C}$. Freeze-vacuum drying operation was continuously run until the moisture content of the blueberry slices was below $0.5 \%$ (w.b.) in about $24 \mathrm{~h}$. The blueberry powders were prepared by using a plant grinder with a screen through 40 meshes. The dehydration blueberry powders were packed in a sealed dark plastic bag and stored in the refrigerator in $-20^{\circ} \mathrm{C}$ for the further experiments. The standard substances of delphinidin chloride, cyanidin chloride, and pelargonidin chloride were provided by Sigma Corporation.

According to research objectives mentioned above, the research route was developed as shown in Figure 1 to investigate the effects of microwave powers on extraction and degradation of anthocyanin from blueberry powder considering absorption of microwave energy. A step-by-step research mode to be constructed as simulation-analysis-elucidation in Figure 1 reveals the mechanism of microwave powers on extraction kinetic of anthocyanin from blueberry powder.

3.2. Experimental Methods. In MAE, ethanol solvent was selected as the extraction solvent due to its high dielectric properties to absorb much more microwave energy and high solubility for the anthocyanin. According to the preliminary experimental results [8], lyophilized blueberry powder of $2.0000 \pm 0.0005 \mathrm{~g}$ was weighted to put into extraction vessel at ethanol concentration of $60 \%$ and ratio of solid to liquid of $1: 30(\mathrm{~g} / \mathrm{mL})$. The mixture of ethanol and blueberry powder was placed in the extraction vessel. Then the extraction vessel was placed in the center of the microwave workstation (MWS, FISO Technologies Inc., Quebec, Canada) and connected with the temperature sensor. In MAE, the microwave input power was set from $100 \mathrm{~W}$ to $400 \mathrm{~W}$ with $100 \mathrm{~W}$ intervals, and the total extraction time was $80 \mathrm{~s}$ at sampling interval of $10 \mathrm{~s}$. Extraction vial refers to the blueberry powder dissolved in extraction liquid in MAE.

Microwave intensity is introduced to clarify the relationship between the microwave power and sample mass, which is defined as the ratio of microwave power to sample mass, $\mathrm{W} / \mathrm{g}$. Microwave intensities were set to $50 \sim 250 \mathrm{~W} / \mathrm{g}$ with the interval of $50 \mathrm{~W} / \mathrm{g}$. To compare the effects of different microwave intensities on the content of anthocyanin in blueberry, the extraction conditions were set as extraction time of $80 \mathrm{~s}$ and weight of blueberry powder of $2.0000 \pm$ $0.0005 \mathrm{~g}$. According to optimal conditions at preliminary experiment, the ethanol concentration and the ratio of solid to liquid were selected as $60 \%$ and $1: 30$, respectively. The extracts were taken for the further measurements. 
3.2.1. Temperature Measurement. An optical fiber sensor of temperature (FOT-L-SD-C1-F1-M2-R1-ST, FISO Co., Quebec, Canada) was used to measure temperature of extraction vial in MAE.

A glass vessel loading extraction vial was placed in a microwave workstation (MWS, FISO Technologies Inc., Quebec, Canada). The connection tips of optical fiber sensors were interconnected with the ports of a signal decoder fixed on the top of the microwave station. Then the tip of optical fiber sensor of temperature was plugged into extraction liquid to collect temperature at $0.03 \mathrm{~s}$ acquirement interval. The temperature of extraction in MAE was recorded using a computer.

3.2.2. Determination of Anthocyanin Extraction Yield and Degradation Rate. An UV/Vis spectrometer (Lambda 35, Perkin Elmer, Singapore) with a variable wavelength detector was employed to measure the anthocyanin content. The highest absorbance of blueberry extract was achieved at $500 \mathrm{~nm}$ wavelength according to the results from preliminary experiments. The plotting curve was obtained by fitting the absorption and the anthocyanin concentration. Thus, a standard curvilinear equation $\left(R^{2}=0.9989\right)$ was fitted as shown in

$$
A=1.612 C-0.0485 \text {. }
$$

The anthocyanin concentration was calculated by using (8); then the anthocyanin yield can be calculated by taking the calculated anthocyanin concentration into

$$
Y_{1}=\frac{C \times V \times n}{W} \times 100 \%
$$

where $Y_{1}$ is anthocyanin yield, \%,C is concentration of anthocyanin, $\mathrm{mg} / \mathrm{mL}, V$ is the constant volume, $\mathrm{mL}, n$ is the multiple factor of dilution, and $W$ is the total content of anthocyanin in $1 \mathrm{~g}$ raw material, $\mathrm{mg} / \mathrm{g}$.

Anthocyanin residue rate was calculated by determining the absorbance of the residue solution. Anthocyanin degradation rate was calculated by using

$$
Y_{2}=1-Y_{1}-Y_{3} \text {, }
$$

where $Y_{1}$ is anthocyanin yield, $\%, Y_{2}$ is anthocyanin degradation rate, $\%$, and $Y_{3}$ is anthocyanin residue rate, $\%$.

3.2.3. HPLC-MS Analysis Method. Liquid chromatograph mass spectrometer (HPLC-MS) consisted of an HPLC (Agilent 1200) coupled to a diode array detector and mass spectrometer (MSD, SL mode, Agilent, Palo Alto, CA). A reversedphase $\mathrm{C}_{18}$ column $(250 \mathrm{~mm} \times 94.6 \mathrm{~mm}, 5 \mu \mathrm{m}$, Kromasil $)$, preceded by a guard column $(4 \mathrm{~mm} \times 3.0 \mathrm{~mm}$, Kromasil $)$ of the same stationary phase, was used at a flow rate of $1.0 \mathrm{~mL} /$ min. A binary solvent system was employed: 5\% methane acid was used as solvent $A$ and a mixture of $96 \%$ ethanol and $5 \%$ methane acid was used as solvent $\mathrm{B}$. The diode array UV detector (DAD) was set at $520 \mathrm{~nm}$ to record the peak intensity. The gradient elution was carried out as the following procedure: in $0 \sim 30 \mathrm{~min}$, flowing mobile phase A from $90 \%$ to $10 \%$; in $30 \sim 32 \mathrm{~min}$, elution operation using $10 \%$ mobile phase $\mathrm{A}$; in $33 \sim 38 \mathrm{~min}$, elution operation using $90 \%$ mobile phase A. Flow rate was set at $1.0 \mathrm{~mL} / \mathrm{min}$ at room temperature with injection volume of $20 \mu \mathrm{L}$ for samples. A split joint was connected with detector at a flow of $0.3 \mathrm{~mL} / \mathrm{min}$ to the mass spectrometer.

The mass spectrometer was operated in both positive and negative ion modes. The capillary voltage was set to $4.0 \mathrm{kV}$, the cone voltage to $22.0 \mathrm{~V}$, and the extractor voltage to $3.0 \mathrm{~V}$. HPLC-ESI-MS system was operated by using Bruker Daltonics software. The mass scan scope is from $100 \mathrm{~m} / z$ to $2000 \mathrm{~m} / z$. Mixed solution of three chemical compounds standards mentioned (each compound with $0.1 \mathrm{mg} / \mathrm{mL}$ dissolved in $60 \%$ ethanol) in part of the sample preparation and $60 \%$ methanol extract were tested, respectively, by using HPLCMS under the above condition.

3.2.4. Quantitative Analysis of Monomer Compounds of Anthocyanin. HPLC-DAD consisting of a Prominence LC2030C was used to measure monomer compounds of anthocyanin extracted from blueberry powder. A reversed-phase $\mathrm{C}_{18}$ column $(250.0 \mathrm{~mm} \times 94.6 \mathrm{~mm}, 5.0 \mu \mathrm{m}$, Kromasil), preceded by a guard column $(4.0 \mathrm{~mm} \times 3.0 \mathrm{~mm}$, Kromasil $)$ of the same stationary phase, was operated at a flow rate of $1.0 \mathrm{~mL} / \mathrm{min}$. The determination of anthocyanin (delphinidin, cyanidin, and pelargonidin) was performed at $520 \mathrm{~nm}$. Standard samples were injected for identification and quantitative analysis. Three species of standard solution including delphinidin, cyanidin, and pelargonidin were prepared in six different concentrations. HPLC spectra of three anthocyanin standards were presented by using peak area. The regression equations were fitted to describe the relationships between the content of anthocyanin monomer and the peak area of HPLC spectra as follows:

$$
\begin{gathered}
\text { Delphinidin: } Y_{1}=55.03 x_{1}-152.1 \\
\text { Cyanidin: } Y_{2}=34.08 x_{2}-87.9 \\
\text { Pelargonidin: } Y_{3}=31.58 x_{3}-152.4,
\end{gathered}
$$

where $x_{1}, x_{2}, x_{3}$ are, respectively, the content of the anthocyanin standard of delphinidin, cyanidin, and pelargonidin and $Y_{1}, Y_{2}, Y_{3}$ are, respectively, the corresponding standard sample of peak area of the HPLC spectra.

\subsection{Observation of the Microstructure of Blueberry Powder} Cell. To observe the cell wall broken by microwave power, a scanning electron microscopy (SEM) (Hitachi High Technologies Inc., IL, USA) was employed to observe the microstructure of kernel of blueberry powder. The lyophilized blueberry powders of $2.0000 \pm 0.0005 \mathrm{~g}$ from step 3.1 were dissolved with $60 \mathrm{~mL}$ of $60 \%$ ethanol. The mixtures were incubated at room temperature for $80 \mathrm{~s}$; then they were centrifuged at $4000 \mathrm{rpm}$ for $15 \mathrm{~min}$ in a microliter centrifuge (International Equipment, MA, USA). The supernatant was collected for the determination of anthocyanin yield. The residual residue was washed with $60 \%$ ethanol until the residue was colorless, and the residue from washing liquid was collected to calculate anthocyanin residue rate. The residue sample was fixed on 


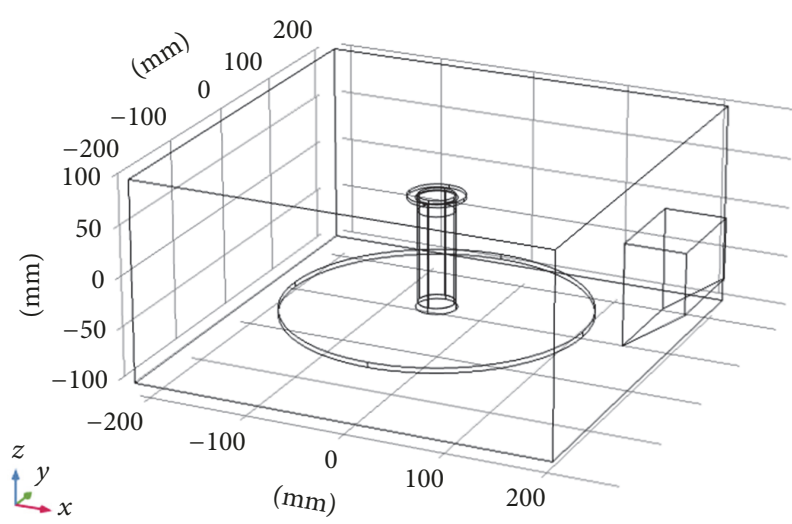

FIGURE 2: Schematic diagram of microwave workstation and extraction vial placement.

a holder using an aluminum tape and sputtered with a thin layer of gold, and then the sample was placed into vacuum cavity with an acceleration voltage of $12.5 \mathrm{kV}$, followed by observation operation. Blueberry powder samples by MAE were prepared as follows. Lyophilized blueberry powders of $2.0000 \pm 0.0005 \mathrm{~g}$ were dissolved with $60 \mathrm{~mL}$ of $60 \%$ ethanol. The mixtures were placed into a microwave station at microwave power of $100 \mathrm{~W}, 200 \mathrm{~W}, 300 \mathrm{~W}$, and $400 \mathrm{~W}$, respectively, for $80 \mathrm{~s}$. The rest of the operation is the same as the raw sample. The residues of blueberry powder were used as blueberry powder samples by MAE, which were used to observe the operation.

3.4. Statistical Analysis. All experiments were conducted in triplicate. The experimental data were presented as mean values with standard deviations. Differences between mean values were established using Duncan's new multiple range tests at a confidence level of 95\%. All statistical calculations were performed using SAS software (8.0, SAS Institute Inc., NC, USA). SigmaPlot software (12.5, Systat Software Inc., USA) was used to fit regression equations according to highest correlation coefficient $\left(R^{2}\right)$ and the lowest standard mean deviation (SMD) value. COMSOL Multiphysics (V5.3a COMSOL Multiphysics, Burlington, MA, USA) software was employed to simulate the absorption of microwave energy in extracts' electric field, temperature, and yield of anthocyanin in extraction vial under different microwave powers. Schematic diagram of microwave workstation and extraction vial placement and the model structure of vial in simulation of COMSOL software were shown in Figures 2 and 3 , respectively. The cylindrical vial was of $100 \mathrm{~mm}$ height and $20 \mathrm{~mm}$ diameter and was marked with five positions at equal distance of $20 \mathrm{~mm}$.

\section{Results and Discussion}

4.1. Absorption of Microwave Energy inside Extraction Vial under Different Microwave Powers. Microwave powers have obviously positive effects on the absorption of microwave energy inside extraction vial. In MAE, the dielectric constant and dielectric loss factor of extraction vial increased with the microwave power. Higher power caused much more extraction yield of anthocyanin with its degradation into charged ions and polar molecules [7]. There are different side groups on the flavylium ion in anthocyanin, which can be a hydrogen atom, a hydroxide, or a methoxy-group [21]. The static dielectric constant increases with the decrease of molecular weights, mainly as a result of increased polarity with the small molecules [10]. Therefore, anthocyanin contains a large number of polar hydroxyl molecules dissolved into extracts to raise the dielectric constant and dielectric loss factor of the extraction vial. In addition, high temperature causes the degradation of anthocyanin to form a chalcone structure to increase the amount of charged ions and polar molecules in extraction vial [22], in which smaller molecules have higher mobility and less relaxation time than those of larger molecules in MAE [23].

The absorption of microwave energy characterizes the utilization of microwave input power, which depends on the changes of dielectric properties of material and electrical field strength. The distributions of microwave energy inside extraction vial under different microwave powers are presented in Figures 4(a)-4(d). The electric strength under different microwave powers had the same distribution trends with high and low area, but increased with the increase of microwave power. These results were attributed to the unchanged distance and position between the extraction vial and port of waveguide of microwave magnetron.

As shown in Figure 4, absorption of microwave energy had obvious nonuniform distribution inside extraction vial at extraction time of $80 \mathrm{~s}$. The absorption amount was at the highest level at the position close to the output of waveguide of magnetron in the microwave workstation. Microwave energy tended to decay trends along the radial of extraction vial from the microwave irradiation direction. The absorption of microwave energy in extraction vial as the function of microwave power is shown as follows [24]:

$$
Q\left(r_{0}-r\right)=\frac{\pi f \varepsilon^{\prime \prime} P_{\text {in }}}{A_{w} \alpha c}\left(1-e^{-2 \alpha\left(r_{0}-r\right)}\right),
$$

where $P_{\text {in }}$ is rated power of microwave applicator, W, $A_{w}$ is cross-sectional area of wave guide, $0.6235 \mathrm{~m}^{2}, c$ is light speed of $3 \times 10^{8} \mathrm{~m} / \mathrm{s}, r_{0}$ is the radium of extraction vessel, $\mathrm{mm}, r$ is position from vessel center along the radium, mm, $\left(r_{0}-r\right)$ is penetration depth of microwave energy along microwave propagation, $\mathrm{mm}$, and $\alpha$ is attenuation factor as follows:

$$
\alpha=\frac{2 \pi}{\lambda_{0}}\left[\frac{\varepsilon^{\prime}}{2}\left(\sqrt{1+\left(\frac{\varepsilon^{\prime \prime}}{\varepsilon^{\prime}}\right)^{2}}-1\right)\right]^{1 / 2} .
$$

In MAE, microwave penetration tended to exponential decay trend along microwave irradiation direction from surface of vessel to center. However, the absorption of microwave energy showed a rising trend from the surface to the center of extraction vessel. The result was attributed to the electrical field distribution under different microwave power. The electrical field had high strength at center location and declined toward surface of extraction vessel in MAE. 


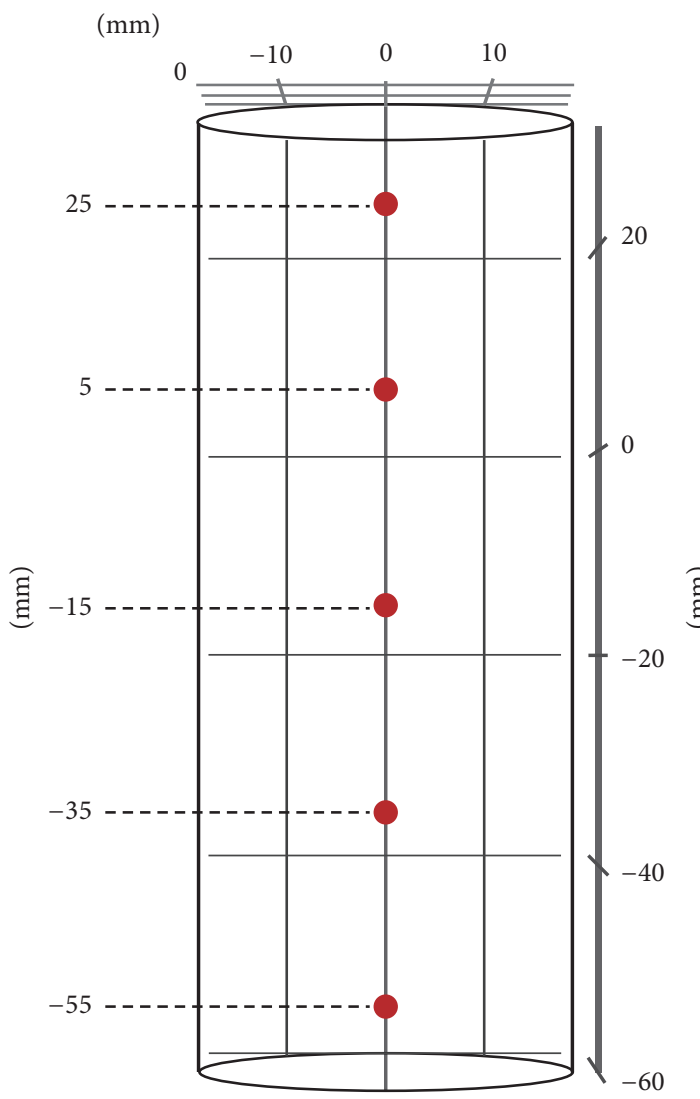

(a)

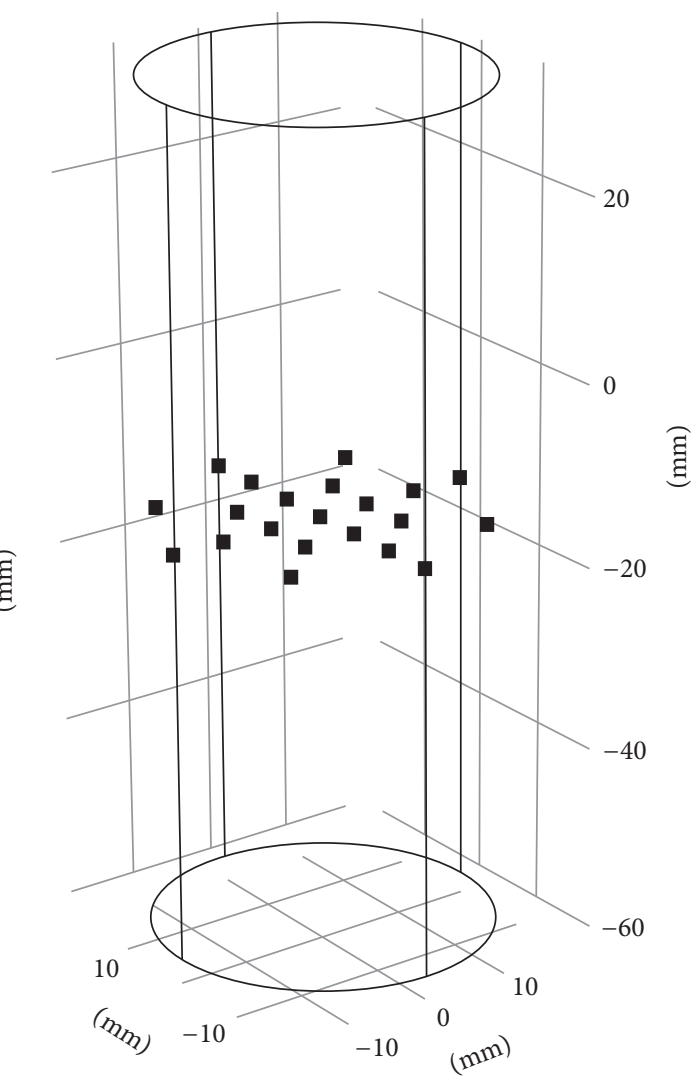

(b)

FIGURE 3: Model structure of vial in simulation of COMSOL software.

The changes of dielectric properties inside extraction vial influence substantially electric field strength. The wavelength and penetration may present microwave transmit within the material along its incident direction as shown in [25]

$$
\begin{aligned}
& \lambda=\frac{2 \pi}{\beta} \\
& L=\frac{1}{2 \alpha},
\end{aligned}
$$

where $\lambda$ is wavelength, $\mathrm{mm}, L$ is penetration depth, $\mathrm{mm}, \alpha$ is attenuation factor, and $\beta$ is phase transfer factor as follows:

$$
\beta=\frac{2 \pi}{\lambda_{0}}\left[\frac{\varepsilon^{\prime}}{2}\left(\sqrt{1+\left(\frac{\varepsilon^{\prime \prime}}{\varepsilon^{\prime}}\right)^{2}}+1\right)\right]^{1 / 2} .
$$

The higher microwave power caused the larger dielectric properties of extraction vial in MAE. The attenuation factor $\alpha$ and phase transfer factor $\beta$ increased with the elevation of dielectric constant and dielectric loss factor to decline wavelength $\lambda$ and penetration depth $L$. For the curved surface of cylinder shape of extraction vessel, transmitted microwaves converge toward center location inside the extraction vial due to large radium under a smaller wavelength and larger penetration depth [26]. This resulted in strong focusing occurrence of electric field strength in extraction vial as shown in Figure 4. The distribution and changes of absorption of microwave energy depend on uneven strength of electric field and rising dielectric properties inside extraction vial. Microwave irradiation has focused effect along the direction of propagation to achieve the strongest strength of electric field at the center [10].

4.2. Effects of Microwave Power on the Profiles of Temperature in the Extraction Vial. The profiles of temperature depend on absorption of microwave energy and the microwave power inside extraction vial. As shown in Figure 5, the temperature of the extraction vial increased with microwave power. The absorption of microwave energy was consumed in thermal accumulation and diffusion inside extraction vial to increase its temperature [27].

As shown in Figure 5, the temperature distribution presented uneven distribution with increasing trends along the radial of the extraction vial. The temperature was the highest at the center of the extraction vital and the top temperature of vial was the lowest under different microwave powers. This was attributed to the highest value of the electric field and the absorption of microwave energy at center location of the extraction vital. Due to the exponential decay of microwave absorption inside extraction vial [28], the distance of propagation had negative effects on the microwave energy flux 


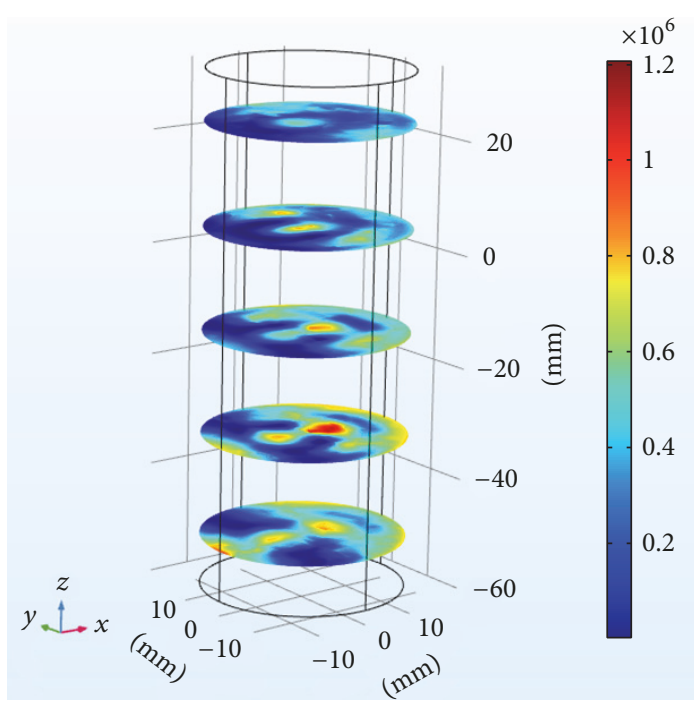

(a) $100 \mathrm{~W}$

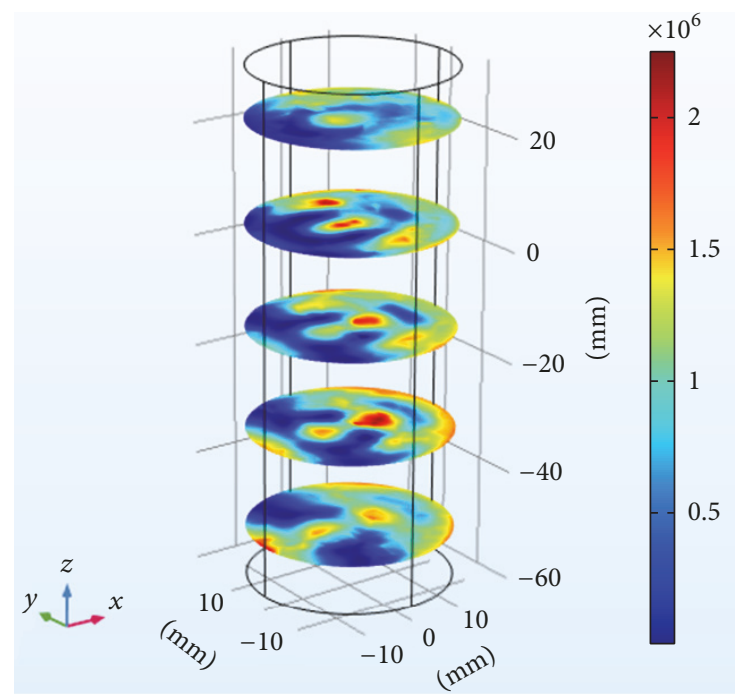

(c) $300 \mathrm{~W}$

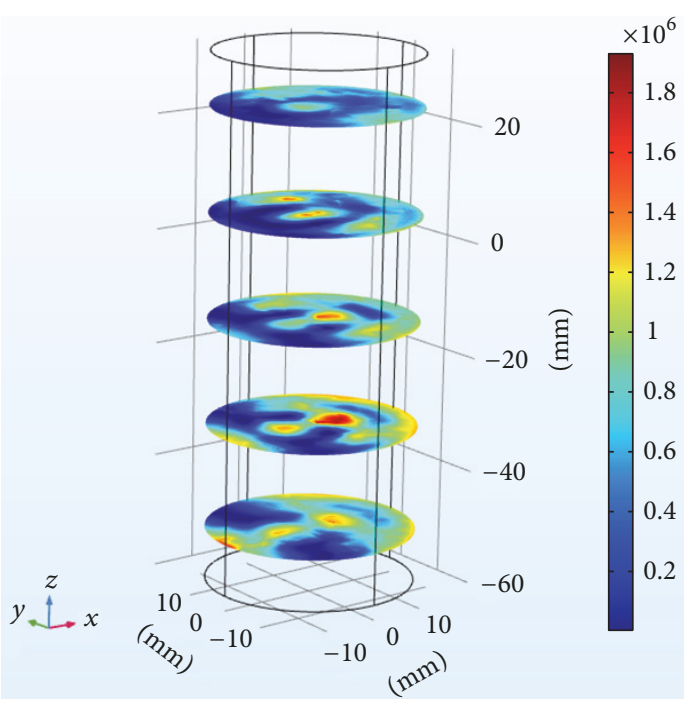

(b) $200 \mathrm{~W}$

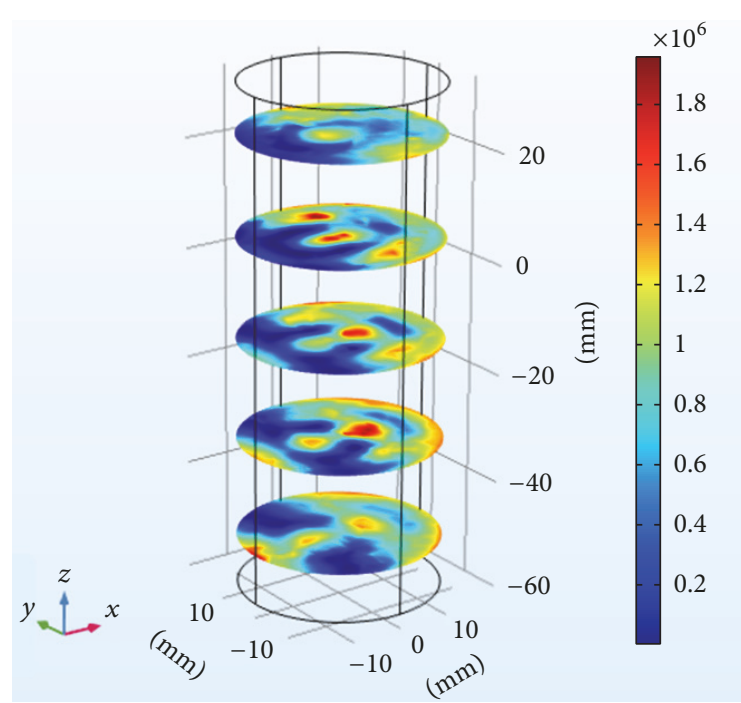

(d) $400 \mathrm{~W}$

FIGURE 4: Distribution of microwave energy absorption in extraction vial at extraction time of $80 \mathrm{~s}$ under 4 microwave powers (ethanol concentration of $60 \%$ and the ratio of solid to liquid of $1: 30$ ).

toward center of vessel along radius. The greater distance of propagation caused less microwave energy absorption, which resulted in the lowest temperature of the extraction vessel bottom [29]. The rotation of glass disc loading extraction vial resulted in the uniformity of heating chance, which smoothes the temperature difference caused by the uneven absorption of microwave energy inside the extraction vial. As shown in Figure 5, the rate of rising temperature in extraction vial was $0.25,0.31$, and $0.1^{\circ} \mathrm{C} / \mathrm{s}$ with the $100 \mathrm{~W}$ increment of microwave power in $100 \sim 400 \mathrm{~W}$ at extraction time of $80 \mathrm{~s}$. Low rising rate of temperature from $76^{\circ} \mathrm{C}$ to $84^{\circ} \mathrm{C}$ in $80 \mathrm{~s}$ at $0.1^{\circ} \mathrm{C} / \mathrm{s}$ was due to boiling state of temperature of extraction vial at $84^{\circ} \mathrm{C}$. The higher microwave power caused the rapider rate of rising temperature. The results provided a theoretical basis for selection of microwave power to improve the efficiency of microwave energy and reduce the degradation of anthocyanin due to local high temperature.

Coefficient of uniform of temperature distribution is as shown in

$$
\mathrm{COU}=\frac{\mathrm{AV}-\mathrm{SE}}{\mathrm{AV}},
$$

where COU is coefficient of uniform of temperature distribution, $\mathrm{AV}$ is average temperature, and SE is the standard error of temperature. COU indicates the discrete degree of temperature data. Higher COU presents more uniform distribution of temperature. As shown in Figure 6, the distribution of temperature had higher COU near the bottom of $-34 \mathrm{~mm}$ and top location of $26 \mathrm{~mm}$ at extraction vial than that of middle location of extraction. The center of outport of 


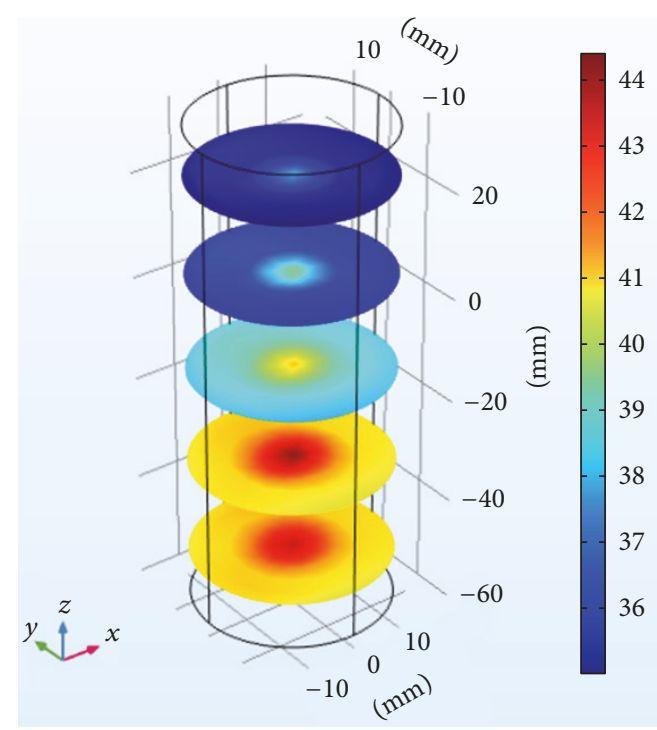

(a) $100 \mathrm{~W}$

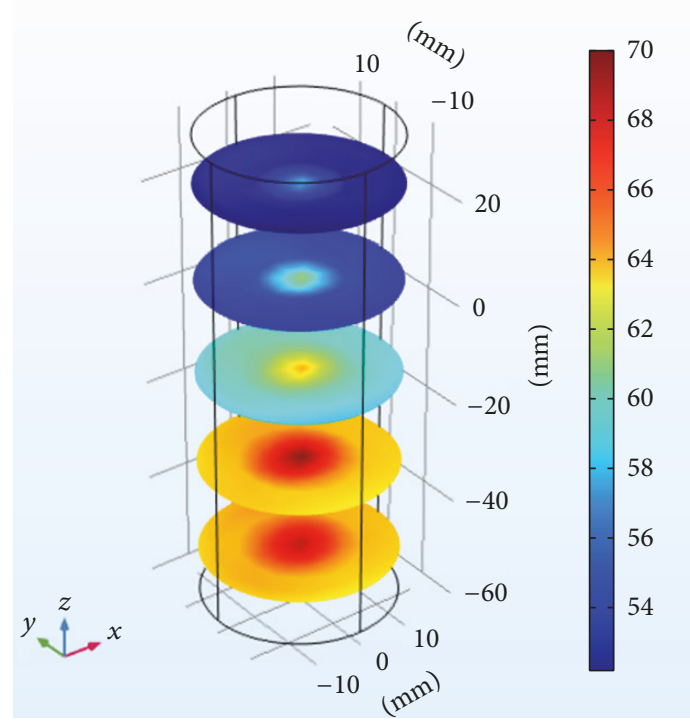

(c) $300 \mathrm{~W}$

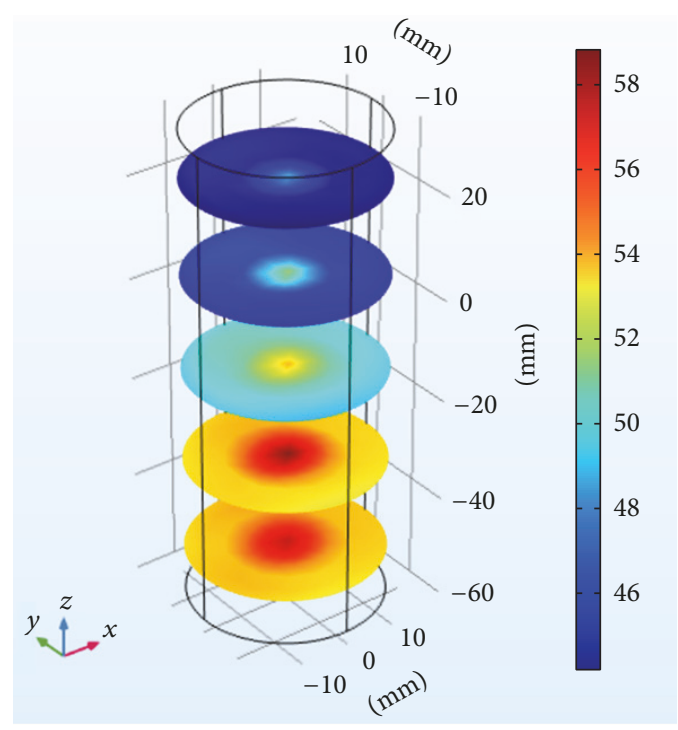

(b) $200 \mathrm{~W}$

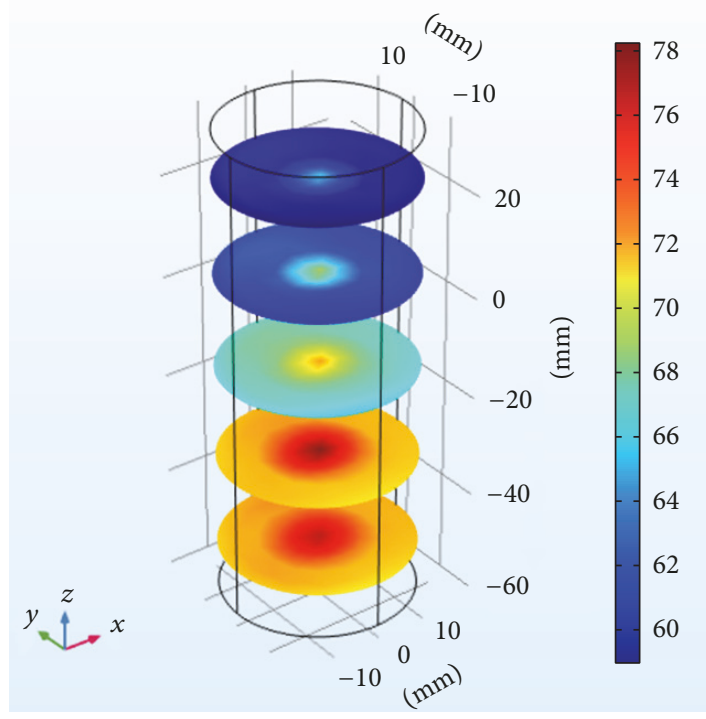

(d) $400 \mathrm{~W}$

Figure 5: Distribution of temperature in extraction vial under 4 microwave powers (ethanol concentration of $60 \%$, ratio of solid to liquid of $1: 30$, and extraction time of $80 \mathrm{~s}$ ).

microwave guidance is as high as $40 \mathrm{~mm}$, in which microwave power directly irradiated the location other than convection to generate high temperature with uniform distribution. The measurements of temperature at top, middle, and bottom location of extraction vial shown in Figure 7 were consistent with the simulation in Figure 5 (400 W).

\subsection{The Effects of Microwave Power on the Anthocyanin} Yield and Degradation Rate. Microwave power is the most important factor in the microwave extraction process, which determines anthocyanin yield and degradation rate. The results are shown in Figure 8.

As shown in Figure 8(a), the anthocyanin yield increased from $63.54 \% \pm 0.57 \%$ to $72.33 \% \pm 0.89 \%$ and
$64.17 \% \pm 0.87 \%$ to $74.52 \% \pm 0.55 \%$ in microwave powers of $100 \mathrm{~W}$ and $200 \mathrm{~W}$, respectively. This phenomenon was attributed to the increase in the temperature of the extract. Rising temperatures contributed to building up intracellular pressure to rupture cell walls and reduce the diffusion resistance of anthocyanin. On the other hand, the increase of temperature resulted in the increase of the solubility of anthocyanin and the decrease of the extracts viscosity [13]. Therefore, anthocyanin in the blueberry cells was more easily diffused from the cells into solvents, which increased anthocyanin yield. The anthocyanin yield tended to obviously increasing trends till $76.58 \% \pm 0.38 \%$ in $50 \mathrm{~s}$ at the temperature of $50.75 \pm 0.88^{\circ} \mathrm{C}(p<0.05)$ and then dropped dramatically in the microwave power of $300 \mathrm{~W}(p<0.05)$. 


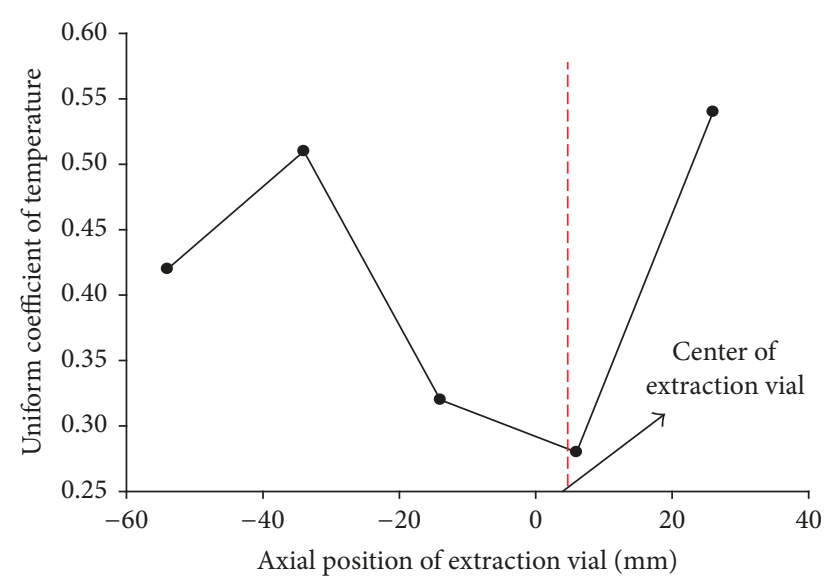

FIGURE 6: Uniform coefficient of temperature distribution along axial position of extraction vial (ethanol concentration of $60 \%$ and the ratio of solid to liquid of $1: 30$ ).

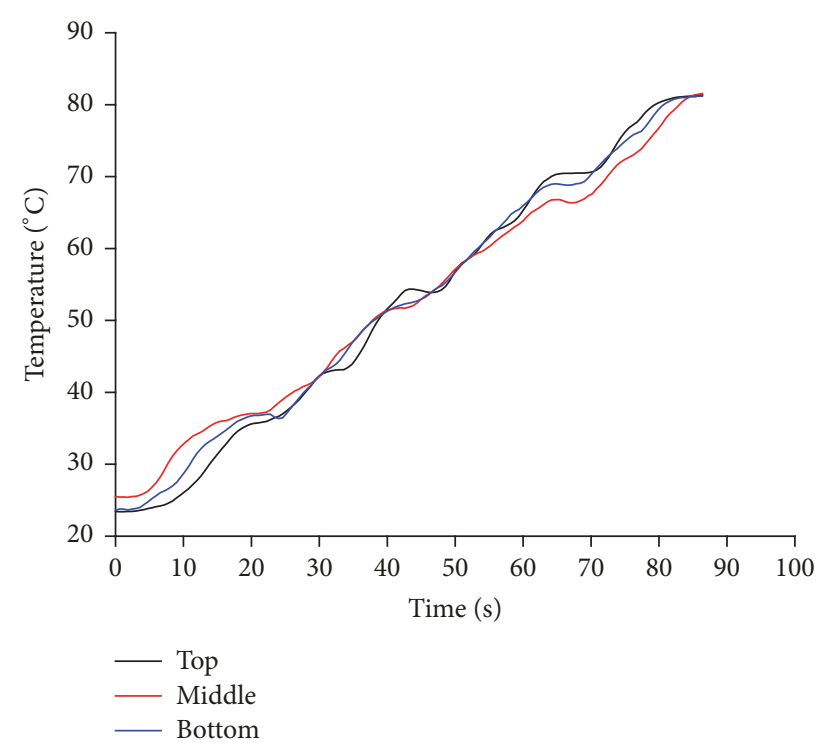

FIgURE 7: Measured temperature of extraction vial in top, middle, and bottom location (microwave power of $400 \mathrm{~W}$, ethanol concentration of $60 \%$, and the ratio of solid to liquid of $1: 30$ ).

The anthocyanin yield initially increased to reach the highest value of $77.51 \% \pm 0.55 \%$ in $30 \mathrm{~s}$ at the temperature of $50.75 \pm 0.88^{\circ} \mathrm{C}$ and then significantly decreased till the extraction end in the microwave power of $400 \mathrm{~W}(p<0.05)$. Based on these results, we deduced that the critical temperature of anthocyanin extraction $\left(T_{d}\right)$ was $50.75 \pm 0.88^{\circ} \mathrm{C}$. The critical temperature indicates that the acquirement of anthocyanins dominates the extraction process in temperatures lower than $T_{d}$ and the degradation of anthocyanin dominates the process in temperatures higher than $T_{d}$. This result is similar to the results of Chumnanpaisont et al. [30] and Sun et al. [7]. As shown in Figure 8(b), the anthocyanin degradation rate significantly increased with the extraction time under different microwave powers $(p<0.05)$. This was because the thermal accumulation caused the local high temperature in the later stage in MAE, which destroyed the anthocyanin structure to increase rate of anthocyanin degradation [31].

4.4. Effects of Microwave Power on the Microstructure of Cell of Blueberry Powders in MAE. Blueberry cell wall is composed of cellulose, hemicellulose, and pectin. Anthocyanin exists in blueberry cells, and the cell wall is a barrier for the diffusion of anthocyanin from the cell. The permeability of cell wall of blueberry powder plays a key role in smooth anthocyanin extraction. The structural changes of blueberry cells of raw and extracted sample were observed by using a SME to understand the extraction effect of the MAE of anthocyanin from blueberry powder. The SME results are shown in Figures 9(a)-9(e). Figure 9(a) showed that the intact blueberry cells were present on the surface of tissues of raw blueberry granules. The microstructure of blueberry granule underwent MAE as shown in Figures 9(b), 9(c), 9(d), and 9 (e) at microwave input power of $100 \mathrm{~W}, 200 \mathrm{~W}, 300 \mathrm{~W}$, and $400 \mathrm{~W}$, respectively, which presented intense damage within blueberry powder. The higher microwave power caused more obvious rupture of cell wall of blueberry powder. The absorption of microwave energy within extraction vial had positive correlation with the microwave power. High absorption of microwave energy caused rapid temperature increase of extraction vial, which resulted in internal pressure build-up and accumulation in blueberry cells [32]. When the internal pressure inside cell of blueberry powder exceeded the yield of cell wall, cell wall was ruptured to release anthocyanin into solvents. Blueberry cell structure might also be thermally damaged due to the thermal degradation of pectin in cellular middle lamella [33]. This result weakened the adhesion between cells and integrity of the cell membrane [34]. This destruction improved the permeability of cell wall to release the anthocyanin existing in cell toward solution, which obviously increased the yield of anthocyanin [35].

4.5. Extraction Kinetic of Anthocyanin under Different Microwave Powers. In MAE, the absorption of microwave energy in extraction vial caused rapid increase of its temperature. However, excessively high extraction temperature may cause the degradation of extracted components [7]. According to the yield of three species of anthocyanin monomers of the experimental data in MAE shown in Figure 10, regression coefficients of (7) were fitted as shown in Table 1. The highest yield of pelargonidin, cyaniding, and delphinidin was, respectively, $1.02,0.54$, and $0.30 \mu \mathrm{g} / \mathrm{mL}$ at microwave intensity of 109,108 , and $120 \mathrm{~W} / \mathrm{g}$. It was observed that blueberry powder settled at the bottom of the vial along axis of $-40 \sim-60 \mathrm{~mm}$ shown in Figure 6 in MAE. The distribution of temperature tended to center high and edge low trends. The temperature domain of blueberry powder dissolved in vial was, respectively, in range of $40 \sim 45^{\circ} \mathrm{C}, 53 \sim 58^{\circ} \mathrm{C}, 61 \sim 70^{\circ} \mathrm{C}$, and $71 \sim 78^{\circ} \mathrm{C}$ at microwave powers of $100 \mathrm{~W}, 200 \mathrm{~W}, 300 \mathrm{~W}$, and $400 \mathrm{~W}$. The improvement of high microwave power on the yield of anthocyanin was attributed to the cell wall broken to release the anthocyanin existing in cell toward solution and the decrease of solvent viscosity to effectively speed up the diffusivity of solvent and solute within extraction vial, which 


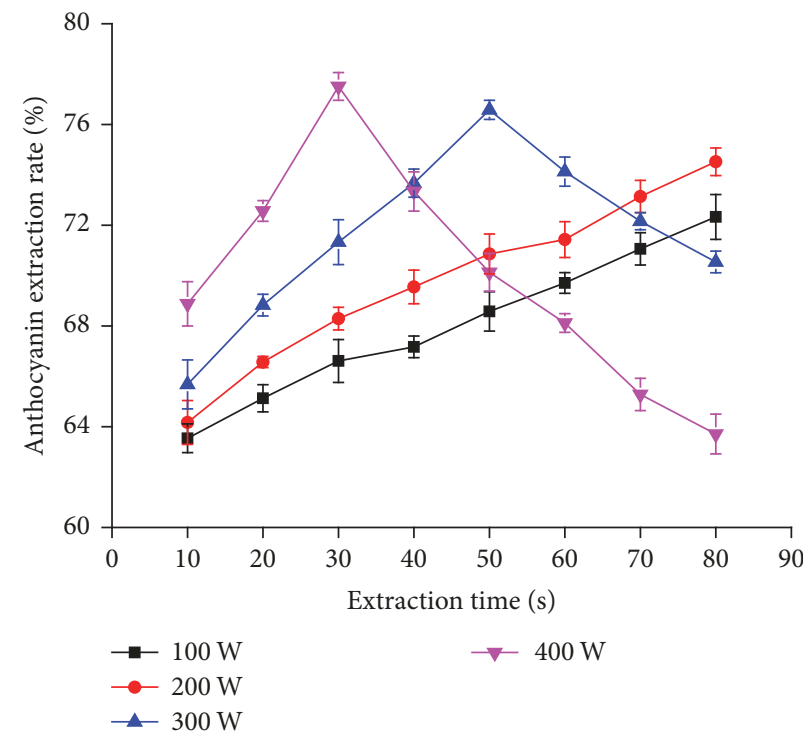

(a)

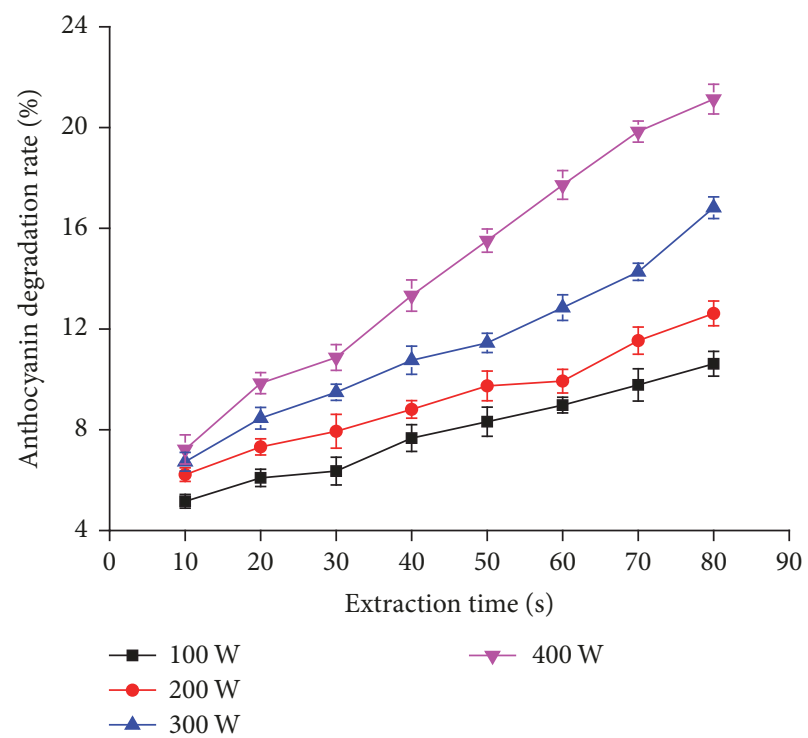

(b)

FIGURE 8: Effects of microwave power on anthocyanin yield (a) and degradation rate (b).

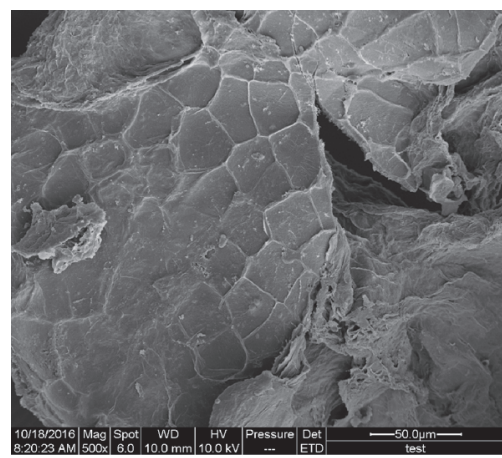

(a) Raw sample

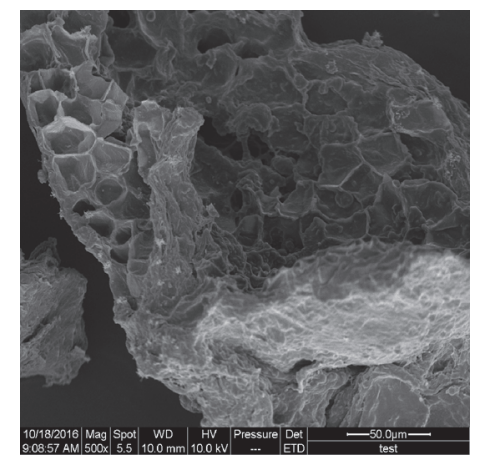

(b) $100 \mathrm{~W}$

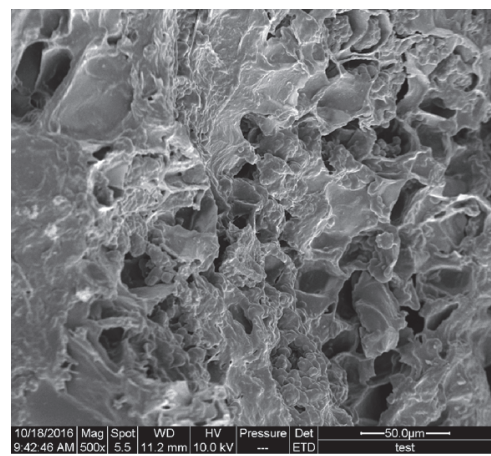

(c) $200 \mathrm{~W}$

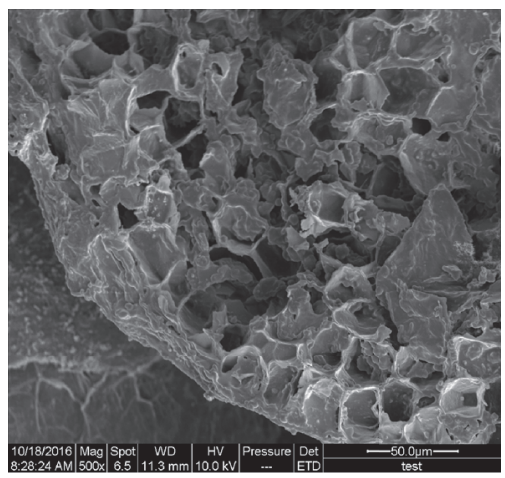

(d) $300 \mathrm{~W}$

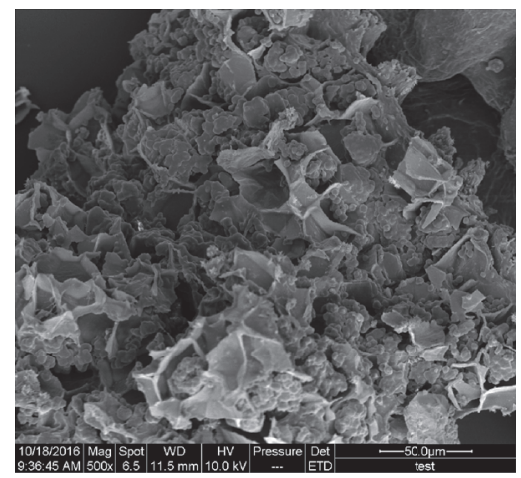

(e) $400 \mathrm{~W}$

FIGURE 9: Microstructure of blueberry powder of raw sample and those extracted by microwave powers.

increased the solubility of anthocyanin in solution [36]. But high microwave power induced anthocyanin degradation in the later stage of extraction due to local high temperature [37].

Anthocyanin of blueberry contains three monomers including delphinidin, cyanidin, and pelargonidin which were detected by using LC-MS. As shown in Figure 10, the changes of the extraction and degradation of the three anthocyanin monomers were obtained under different microwave intensities. The results from Figure 10 indicated that pelargonidin content was the highest, followed by cyaniding content, and delphinidin content was the lowest. Under the microwave power of $50 \mathrm{~W} / \mathrm{g}$, the temperature of extraction vial achieved 


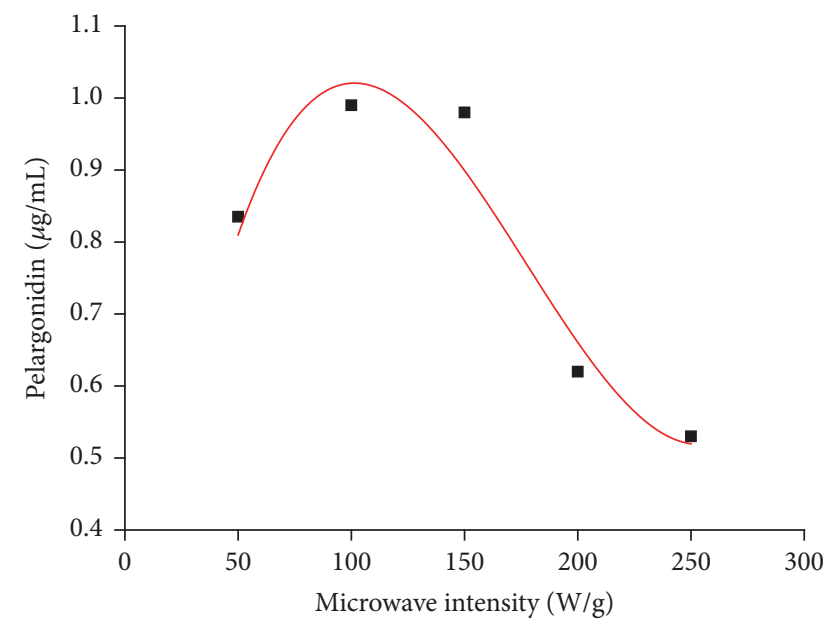

(a)

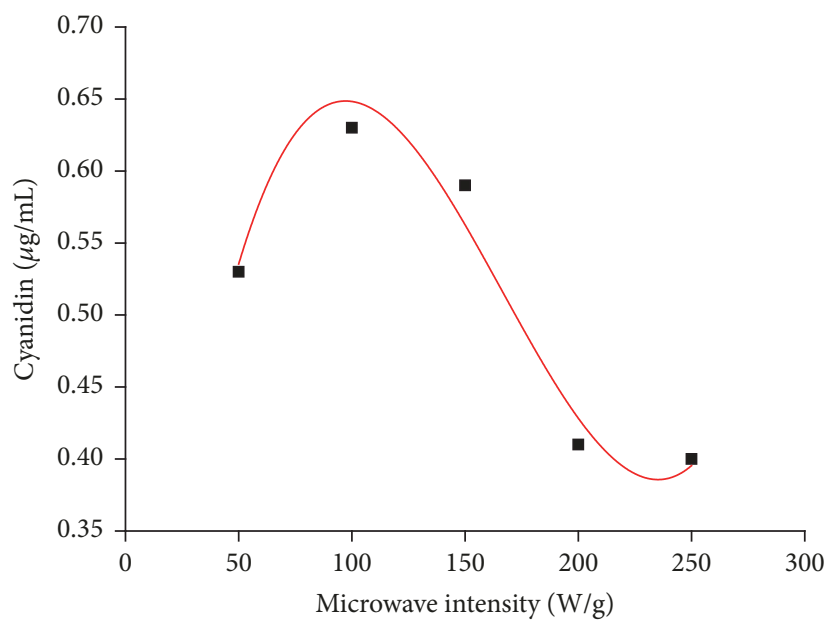

(b)

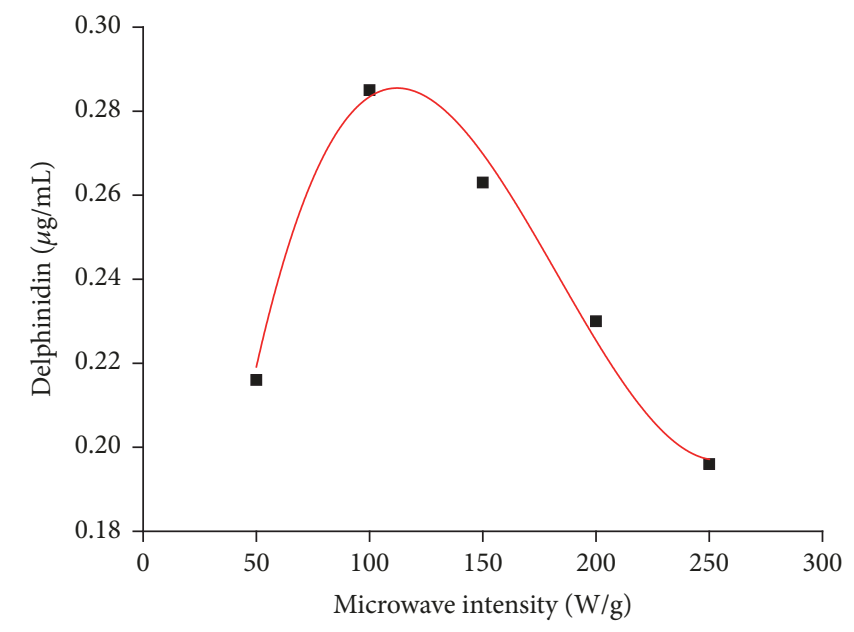

(c)

Figure 10: Effects of microwave intensities on the anthocyanin monomer (ethanol concentration of $60 \%$, ratio of solid to liquid of $1: 30$, and extraction time of $80 \mathrm{~s})$.

TABLE 1: Regression parameters of degradation kinetic of anthocyanin monomer in (7).

\begin{tabular}{lccccc}
\hline Monomer species & $a$ & $k$ & $x_{0}$ & $Y_{0}$ & $R^{2}$ \\
\hline Pelargonidin & 0.7553 & 99.664 & 109.2059 & 0.2600 & 0.9546 \\
Cyanidin & 0.3472 & 74.3394 & 107.5474 & 0.1923 & 0.9413 \\
Delphinidin & 0.1119 & 43.8381 & 120.3687 & 0.1923 & 0.0451 \\
\hline
\end{tabular}

$40 \sim 45^{\circ} \mathrm{C}$. The extraction temperature is too low to produce sufficient energy to extract the anthocyanin from blueberry powder. When the microwave power was at $100 \mathrm{~W} / \mathrm{g}$, the temperature of the extracts was $53 \sim 58^{\circ} \mathrm{C}$ and the content of each component reached the maximum value. This temperature was close to the critical temperature of anthocyanin extraction of $50.75 \pm 0.88^{\circ} \mathrm{C}$. When the microwave power was higher than $100 \mathrm{~W} / \mathrm{g}$, the temperature of the extracts was greater than $61 \sim 70^{\circ} \mathrm{C}$, which induced the degradation of anthocyanin [38].

\section{Conclusions}

There exists obviously nonuniform distribution of absorption of microwave power and temperature in extraction vial. The uniform temperature distribution is higher near bottom and top location than that of middle location of extraction vial; however, microwave power presents nonsignificant effect on uniform temperature distribution. Microstructure of cell wall of blueberry powders indicates that high microwave power intensively ruptures the cell wall of blueberry to weaken 
obvious diffusion resistance of interior anthocyanin toward extraction solvent. Pelargonidin content was the highest, followed by cyaniding content, and delphinidin content was the lowest for the anthocyanin extracted from blueberry powders in MAE. The research results suggested that the controlling microwave power contributes to the improvement of anthocyanin yield and efficiency of microwave energy.

\section{Conflicts of Interest}

The authors declare that they have no conflicts of interest.

\section{Acknowledgments}

The authors gratefully acknowledge the financial support provided by the National Natural Science Foundation of China (31571848) for this research project.

\section{References}

[1] M. Zielinska and A. Michalska, "Microwave-assisted drying of blueberry (Vaccinium corymbosum L.) fruits: drying kinetics, polyphenols, anthocyanins, antioxidant capacity, colour and texture," Food Chemistry, vol. 212, pp. 671-680, 2016.

[2] I. E. Garofulić, V. Dragović-Uzelac, A. R. Jambrak, and M. Jukić, "The effect of microwave assisted extraction on the isolation of anthocyanins and phenolic acids from sour cherry Marasca (Prunus cerasus var. Marasca)," Journal of Food Engineering, vol. 117, no. 4, pp. 437-442, 2013.

[3] R. Y. Krishnan and K. S. Rajan, "Microwave assisted extraction of flavonoids from Terminalia bellerica: study of kinetics and thermodynamics," Separation and Purification Technology, vol. 157, pp. 169-178, 2016.

[4] S. S. Hosseini, F. Khodaiyan, and M. S. Yarmand, "Optimization of microwave assisted extraction of pectin from sour orange peel and its physicochemical properties," Carbohydrate Polymers, vol. 140, pp. 59-65, 2016.

[5] E. Durmaz, G. Sumnu, and S. Sahin, "Microwave-assisted extraction of phenolic compounds from caper," Separation Science and Technology, vol. 50, no. 13, pp. 1986-1992, 2015.

[6] M. Taghvaei, S. M. Jafari, S. Nowrouzieh, and O. Alishah, "The influence of cooking process on the microwave-assisted extraction of cottonseed oil," Journal of Food Science and Technology, vol. 52, no. 2, pp. 1138-1144, 2013.

[7] Y. Sun, H. K. Xue, C. H. Liu, C. Liu, X. L. Su, and X. Z. Zheng, "Comparison of microwave assisted extraction with hot reflux extraction in acquirement and degradation of anthocyanin from powdered blueberry," International Journal of Agricultural and Biological Engineering, vol. 9, no. 6, pp. 186-199, 2016.

[8] X. Zheng, X. Xu, C. Liu, Y. Sun, Z. Lin, and H. Liu, "Extraction characteristics and optimal parameters of anthocyanin from blueberry powder under microwave-assisted extraction conditions," Separation and Purification Technology, vol. 104, no. 5, pp. 17-25, 2013.

[9] M. Golmakani and M. Moayyedi, " Comparison of heat and mass transfer of different microwave-assisted extraction methods of essential oil from " Food Science \& Nutrition, vol. 3, no. 6, pp. 506-518, 2015.

[10] C. Liu, C. Liu, H. Xue et al., "Effect of microwave energy dissipation on drying process of berry puree under microwave foam drying conditions," Drying Technology, vol. 35, no. 11, pp. 13881397, 2017.
[11] T. Santos, M. A. Valente, J. Monteiro, J. Sousa, and L. C. Costa, "Electromagnetic and thermal history during microwave heating," Applied Thermal Engineering, vol. 31, no. 16, pp. 3255-3261, 2011.

[12] G. Z. Han, M. D. Chen, P. S. Guo, and S. X. Li, "Absorption coefficient and absorption density of microwave energy of microwave in microwave assisted extraction," Journal of South China University of Technology, vol. 35, pp. 52-57, 2007.

[13] C.-H. Chan, J.-J. Lim, R. Yusoff, and G.-C. Ngoh, "A generalized energy-based kinetic model for microwave-assisted extraction of bioactive compounds from plants," Separation and Purification Technology, vol. 143, pp. 152-160, 2015.

[14] C.-H. Chan, R. Yusoff, and G.-C. Ngoh, "Modeling and prediction of extraction profile for microwave-assisted extraction based on absorbed microwave energy," Food Chemistry, vol. 140, no. 1-2, pp. 147-153, 2013.

[15] K. Pitchai, S. L. Birla, J. Subbiah, D. Jones, and H. Thippareddi, "Coupled electromagnetic and heat transfer model for microwave heating in domestic ovens," Journal of Food Engineering, vol. 112, no. 1-2, pp. 100-111, 2012.

[16] J. I. Lombraña, R. Rodríguez, and U. Ruiz, "Microwave-drying of sliced mushroom. Analysis of temperature control and pressure," Innovative Food Science and Emerging Technologies, vol. 11, no. 4, pp. 652-660, 2010.

[17] A. Patil and A. K. Singh, "Effect of enzyme and microwave pretreatment on oil recovery from canola," Journal of Food Process Engineering, vol. 40, no. 1, Article ID e12340, 2016.

[18] A. Navarrete, R. B. Mato, and M. J. Cocero, "A predictive approach in modeling and simulation of heat and mass transfer during microwave heating. Application to SFME of essential oil of Lavandin Super," Chemical Engineering Science, vol. 68, no. 1, pp. 192-201, 2012.

[19] K. Sinha, P. D. Saha, and S. Datta, "Response surface optimization and artificial neural network modeling of microwave assisted natural dye extraction from pomegranate rind," Industrial Crops and Products, vol. 37, no. 1, pp. 408-414, 2012.

[20] L. Zhen, Dielectric properties of berry fruit under microwave processing [Ph.D. thesis], Northeast Agricultural University, Harbin, China, 2013.

[21] A. Martynenko and Y. Chen, "Degradation kinetics of total anthocyanins and formation of polymeric color in blueberry hydrothermodynamic (HTD) processing," Journal of Food Engineering, vol. 171, pp. 44-51, 2016.

[22] A. Patras, N. P. Brunton, C. O’Donnell, and B. K. Tiwari, “Effect of thermal processing on anthocyanin stability in foods; mechanisms and kinetics of degradation," Trends in Food Science \& Technology, vol. 21, no. 1, pp. 3-11, 2010.

[23] The Microwave Processing of Foods, Woodhead Publishing, Duxford, UK, 2nd edition, 2017.

[24] X. Zheng, Y. Wang, C. Liu et al., "Microwave energy absorption behavior of foamed berry puree under microwave drying conditions," Drying Technology, vol. 31, no. 7, pp. 785-794, 2013.

[25] H. Zhang and A. K. Datta, "Heating concentrations of microwaves in spherical and cylindrical foods," Food and Bioproducts Processing, vol. 83, no. 1, pp. 14-24, 2005.

[26] H. Zhang and A. K. Datta, "Heating concentrations of microwaves in spherical and cylindrical foods," Food and Bioproducts Processing, vol. 83, no. 1, pp. 6-13, 2005.

[27] W. Sookjitsumran, S. Devahastin, A. S. Mujumdar, and N. Chiewchan, "Comparative evaluation of microwave-assisted extraction and preheated solvent extraction of bioactive compounds from a plant material: a case study with cabbages," 
International Journal of Food Science \& Technology, vol. 51, no. 11, pp. 2440-2449, 2016.

[28] C.-H. Chan, H. K. Yeoh, R. Yusoff, and G. C. Ngoh, "A first-principles model for plant cell rupture in microwaveassisted extraction of bioactive compounds," Journal of Food Engineering, vol. 188, pp. 98-107, 2016.

[29] D. M. Patil and K. G. Akamanchi, "Microwave assisted process intensification and kinetic modelling: extraction of camptothecin from Nothapodytes nimmoniana plant," Industrial Crops and Products, vol. 98, pp. 60-67, 2017.

[30] N. Chumnanpaisont, C. Niamnuy, and S. Devahastin, "Mathematical model for continuous and intermittent microwaveassisted extraction of bioactive compound from plant material: Extraction of $\beta$-carotene from carrot peels," Chemical Engineering Science, vol. 116, pp. 442-451, 2014.

[31] X. Zheng, X. Wang, Y. Lan, J. Shi, S. J. Xue, and C. Liu, "Application of response surface methodology to optimize microwave-assisted extraction of silymarin from milk thistle seeds," Separation and Purification Technology, vol. 70, no. 1, pp. 34-40, 2009.

[32] P. Pongmalai, S. Devahastin, N. Chiewchan, and S. Soponronnarit, "Enhancement of microwave-assisted extraction of bioactive compounds from cabbage outer leaves via the application of ultrasonic pretreatment," Separation and Purification Technology, vol. 144, pp. 37-45, 2015.

[33] Y. Ando, S. Hagiwara, and H. Nabetani, “Thermal inactivation kinetics of pectin methylesterase and the impact of thermal treatment on the texture, electrical impedance characteristics and cell wall structure of Japanese radish (Raphanus sativus L.)," Journal of Food Engineering, vol. 199, pp. 9-18, 2017.

[34] Y. Xin, M. Zhang, B. Xu, B. Adhikari, and J. Sun, "Research trends in selected blanching pretreatments and quick freezing technologies as applied in fruits and vegetables: a review," International Journal of Refrigeration, vol. 57, article no. 3030, pp. 11-25, 2015.

[35] X. Sun, W. Li, J. Li et al., "Process optimisation of microwaveassisted extraction of peony (Paeonia suffruticosa Andr.) seed oil using hexane-ethanol mixture and its characterisation," International Journal of Food Science and Technology, vol. 51, no. 12, pp. 2663-2673, 2016.

[36] X. Zheng, F. Yin, C. Liu, and X. Xu, "Effect of process parameters of microwave assisted extraction (MAE) on polysaccharides yield from pumpkin," Journal of Northeast Agricultural University (English edition), vol. 18, no. 2, pp. 79-86, 2011.

[37] J. R. Sarkis, D. P. Jaeschke, I. C. Tessaro, and L. D. F. Marczak, "Effects of ohmic and conventional heating on anthocyanin degradation during the processing of blueberry pulp," LWTFood Science and Technology, vol. 51, no. 1, pp. 79-85, 2013.

[38] W. J. Liu, X. Wang, and J. H. Du, "Review on isolation, purification and qualitative and quantitative analysis method of anthocyanin," China Food Additives, vol. 6, pp. 178-182, 2010. 


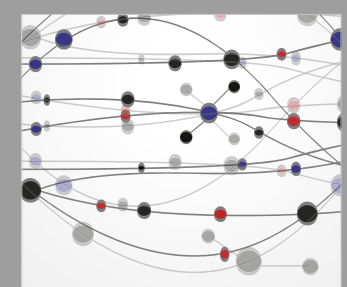

The Scientific World Journal
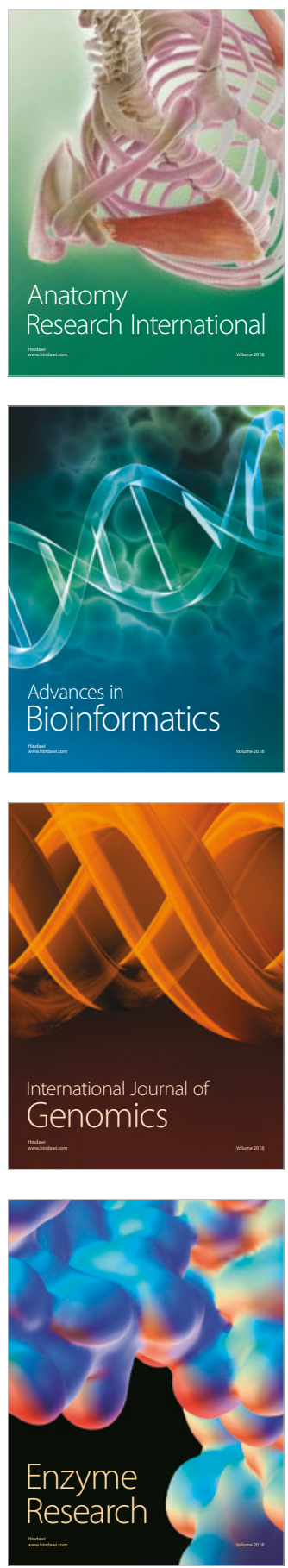
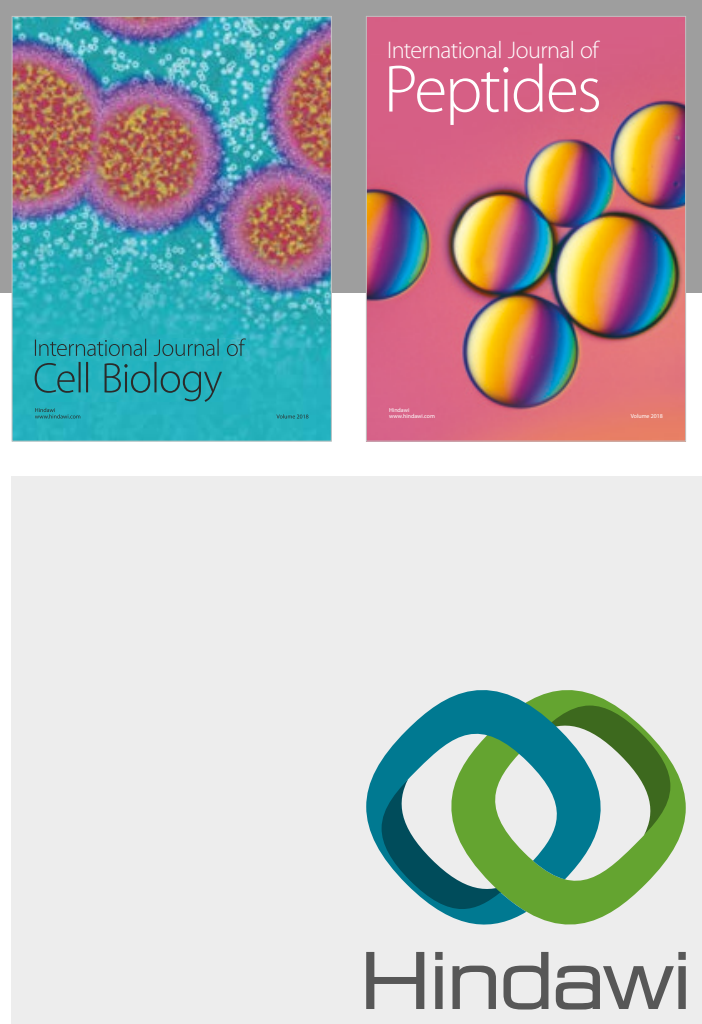

Submit your manuscripts at

www.hindawi.com
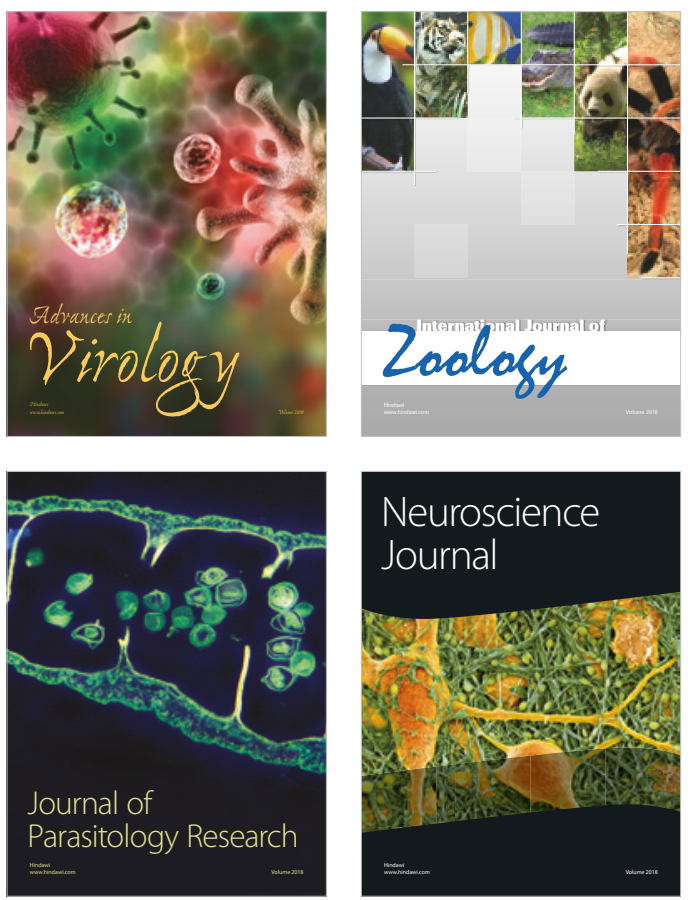
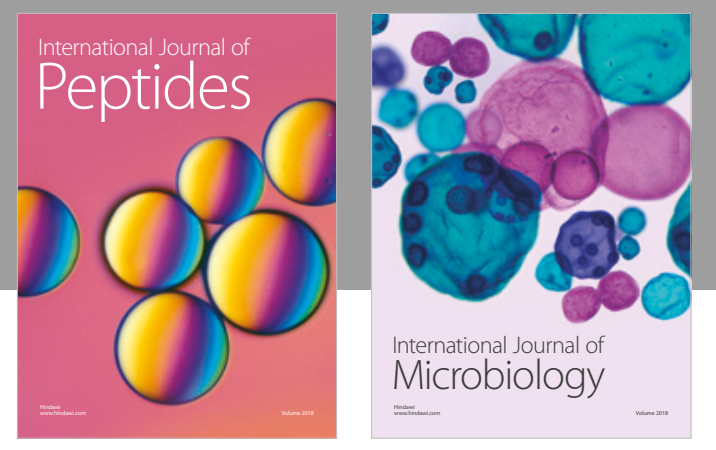

nternational Journal of Microbiology
Journal of
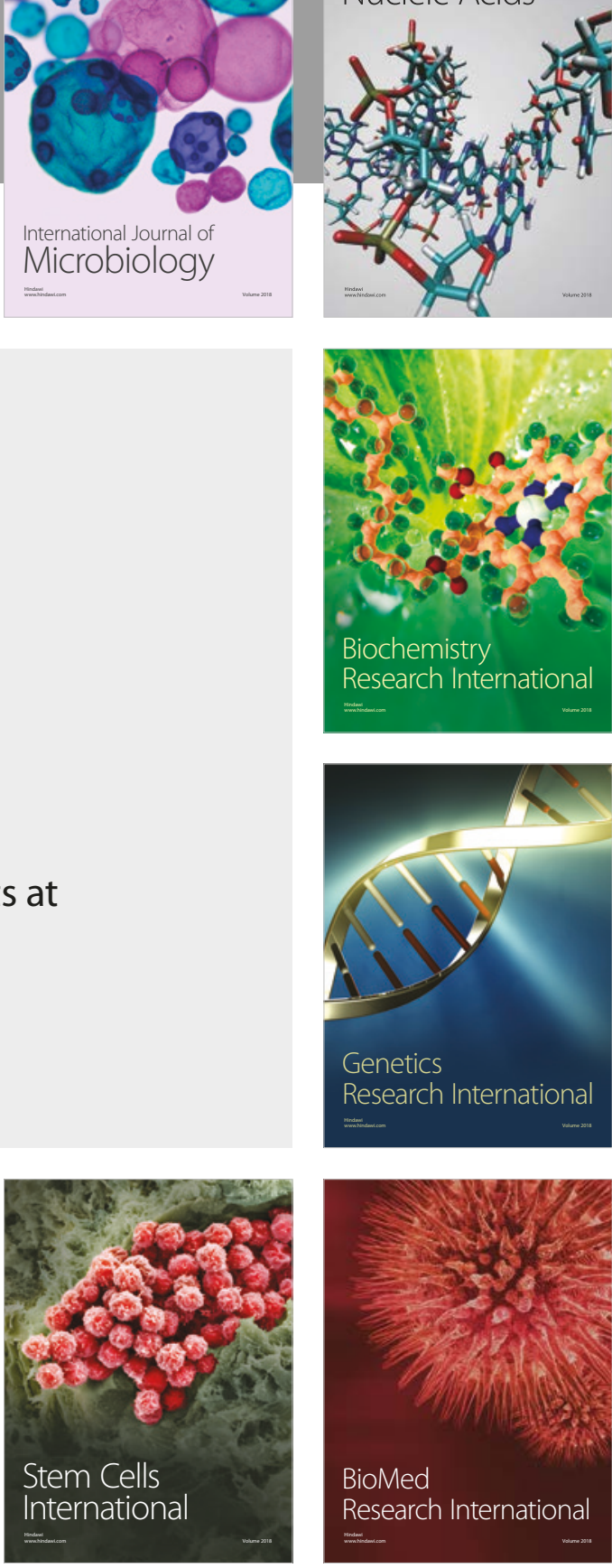
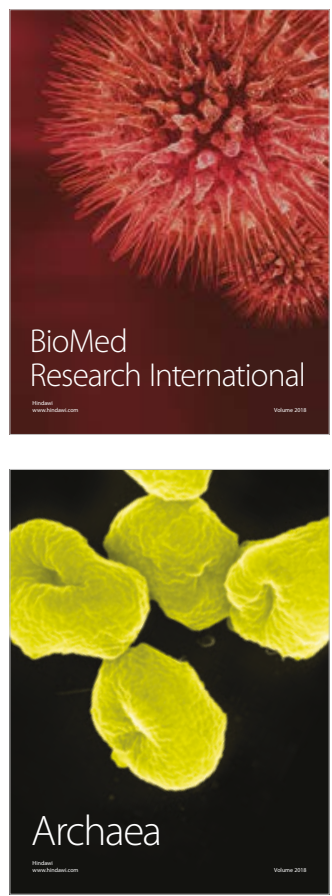